\title{
Optimisation of a Novel
}

Bio-Substrate as a Treatment for Atrophic Age-Related Macular Degeneration

\section{OPEN ACCESS}

Edited by:

Dimitrios I. Zeugolis,

National University of Ireland Galway,

Ireland

Reviewed by:

Christine A. Curcio,

University of Alabama at Birmingham,

United States

Thomas Ach,

University Hospital Würzburg,

Germany

*Correspondence:

Atikah Hanee

atikahh@liverpool.ac.uk

Specialty section:

This article was submitted to

Tissue Engineering and Regenerative

Medicine,

a section of the journal

Frontiers in Bioengineering and

Biotechnology

Received: 20 December 2019

Accepted: 21 April 2020

Published: 15 May 2020

Citation:

McCormick R, Pearce I, Kaye S

and Haneef $A$ (2020) Optimisation

of a Novel Bio-Substrate as

a Treatment for Atrophic Age-Related

Macular Degeneration.

Front. Bioeng. Biotechnol. 8:456.

doi: 10.3389/fbioe.2020.00456

\begin{abstract}
Rachel McCormick ${ }^{1}$, lan Pearce ${ }^{2}$, Stephen Kaye ${ }^{1,2}$ and Atikah Haneef ${ }^{1 *}$
'Department of Eye and Vision Science, Institute of Life Course and Medical Sciences, University of Liverpool, Liverpool, United Kingdom, ${ }^{2}$ St Paul's Eye Unit, Royal Liverpool University Hospital, Liverpool, United Kingdom
\end{abstract}

Atrophic age-related macular degeneration (AMD) is the most common form of AMD accounting for $90 \%$ of patients. During atrophic AMD the waste/exchange pathway between the blood supply (choroid) and the retinal pigment epithelium (RPE) is compromised. This results in atrophy and death of the RPE cells and subsequently the photoreceptors leading to central blindness. Although the mechanisms behind AMD are unknown, the growth of fatty deposits known as drusen, have been shown to play a role in the disease. There is currently no treatment or cure for atrophic AMD. Much research focuses on developing a synthetic substrate in order to transplant healthy cells to the native Bruch's membrane (BM), however, the diseased native BM and related structures still leave potential for transplanted cells to succumb to disease. In this proof-of-concept work we electrospun poly(ethylene terephthalate) (PET) to fabricate a nanofibrous cytocompatible synthetic BM. The apical surface of the membrane was cultured with ARPE-19 cells and the underside was decorated with poly(lactic acid-co-glycolic acid) (PLGA) or poly(glycolic acid) (PGA) degradable nanoparticles by electrospraying. The membrane exhibited hydrophilicity, high tensile strength and structurally resembled the native BM. ARPE-19 cells were able to form a monolayer on the surface of the membrane and no cell invasion into the membrane was seen. The presence of both PLGA and PGA nanoparticles increased ARPE-19 cell metabolism but had no effect on cell viability. There was a decrease in $\mathrm{pH}$ of ARPE-19 cell culture media 7 days following culturing with the PLGA nanoparticles but this change was eliminated by 2 weeks; PGA nanoparticles had no effect on cell culture media $\mathrm{pH}$. The fluorescent dye FITC was encapsulated into nanoparticles and showed sustained release from PLGA nanoparticles for 2 weeks and PGA nanoparticles for 1 day. Future work will focus on encapsulating biologically active moieties to target drusen. This could allow this novel bioactive substrate to be a potential treatment for atrophic AMD that would function twofold: deliver the required monolayer of healthy RPE cells to the macula on a synthetic $\mathrm{BM}$ and remove diseased structures within the retina, restoring the waste/exchange pathway and preventing vision loss.

Keywords: AMD, electrospinning, electrospraying, nanoparticles, sustained release, composite, substrate, coaxial 


\section{INTRODUCTION}

Age-related macular degeneration (AMD) is a progressive disease of the retina that is the leading form of blindness in developed countries. It is a form of central blindness that mainly affects people over the age of 50 years. Although the pathology of AMD is currently unknown, age is considered to be the main contributing factor to the manifestation of this disease (Nowak, 2006; Curcio and Johnson, 2013). There are two forms of AMD; neovascular and atrophic (nonexudative). Neovascular (or wet) AMD makes up $10 \%$ of all reported cases where new abnormal leaking blood vessels break through a layer underlying the retina called the BM leading to a loss of central vision. There has been significant developments and improvements in the management of neovascular AMD such as intravitreal injections of antivascular endothelial growth factor (anti-VEGF) to prevent any further growth of abnormal blood vessels. Nonexudative (or dry) AMD, however, makes up $90 \%$ of all cases. It is associated with a slowly progressive form of sight loss where fatty deposits known as drusen, form on BM leading to alterations and atrophy of the RPE. The RPE is the main source of nutrient/waste exchange; if the RPE fails it leads on to photoreceptor death, ultimately leading to central blindness (atrophic AMD) as the end stage of the disease. Although several risk factors for nonexudative AMD are known, there are no available treatments other than supportive optical aids and nutritional supplements that are recommended for a subset of patients with large drusen (Rudolf et al., 2008; Age-Related Eye Disease Study 2 Research Group, 2013).

Much research focuses on developing a synthetic cell transplantation substrate in order to transplant healthy RPE cells onto BM as a treatment for nonexudative AMD (Lu et al., 2012; Liu et al., 2014; Surrao et al., 2017; da Cruz et al., 2018; Tan et al., 2019). The underlying native diseased BM and related structures remain, however, which leaves the potential for healthy transplanted cells to eventually succumb to disease (White and Olabisi, 2017).

Recent research has explored using an anti-inflammatory, antiatherogenic peptide L-4F to reduce the accumulation of fatty deposits on BM of Macaca fascicularis, via intravitreal injection of L-4F (Rudolf et al., 2019). Those eyes injected with L-4F were found to have had clearance of the fatty deposits along the BM without harming surrounding ultrastructure in the retina. This is particularly interesting, as they described the drug to be well tolerated at even the highest dose, with the only adverse events attributed to the physical process of the injection. Interestingly they found that the effect of the drug was seen bilaterally, even though only one eye was injected with the drug while the other was meant to serve as a control (Rudolf et al., 2019).

Abbreviations: AMD, aged related macular degeneration; Best1, bestrophin 1; BM, bruch's membrane; DAPI, 4'6-diamidino-2-phenylindole; DMEM, dulbecco's modified eagles' media; DPBS, dulbecco's phosphate buffered saline; FITC, fluorescein-5-isothiocyanate; FTIR, fourier-transform infrared spectroscopy; NBF, neutral buffered formalin; PET, poly(ethylene terephthalate); PGA, poly(glycolic acid); PLGA, poly(lactic acid-co-glycolic acid); RPE, retinal pigment epithelium; SEM, scanning electron microscope; UTS, ultimate tensile strength; UV, ultraviolet; VEGF, vascular endothelial growth factor; WCA, water contact angle; YM, young's modulus.
There is, therefore, scope to provide a two-pronged approach for a potential treatment for nonexudative AMD. That is, a persistent bioactive substrate that would function two-fold; provide a permanent basement layer for transplantation of healthy RPE cells to the area required, while removing diseased structures (drusen) on the BM (Curcio and Johnson, 2013), using moieties such as L-4F. This would replenish the native BM nutrient/waste exchange pathway, preventing the progressive loss of photoreceptors, through a more controlled and localized effect. Our aim is to develop a bioactive persistent cell transplant substrate for the treatment for nonexudative AMD. This article describes the development of a composite membrane for this two-pronged approach, which includes the fabrication of a nondegradable electrospun membrane (adapted from a previously fabricated and tested membrane (Haneef and Downes, 2015) that will serve as a cell-culture substrate on the membrane's apical surface, nanoparticles are anticipated to be decorated on the underside of the membrane (opposite to where the cells will be cultured) electrosprayed to encapsulate biological moieties for sustained release to locally target drusen. Electrospraying parameters can be altered to control the degradation of the nanoparticles, thereby allowing a controlled release of these moieties. For the purpose of this paper we have encapsulated fluorescent dye FITC into the nanoparticles to exhibit the proofof-concept, we have not yet chosen nor decided upon the biological moiety that would be used to target the drusen.

\section{MATERIALS AND METHODS}

\section{Electrospinning of PET Scaffold}

Poly(ethylene terephthalate) (PET) pellets (04301, Polysciences Inc.) were dissolved in neat 1,1,1-3,3,3-hexafluoroisopropanol (HFIP) (Apollo Scientific Ltd.) at a concentration of $17.5 \%(\mathrm{w} / \mathrm{v})$. The fibres were collected for 15 min under laboratory conditions on a grounded plate covered with aluminium foil at a working distance of $15 \mathrm{~cm}$, flow rate of $2 \mathrm{ml} / \mathrm{h}$ and a voltage of $25 \mathrm{kV}$.

\section{Electrospraying of PLGA and PGA Nanoparticles}

Poly(lactic acid-co-glycolic acid) 50/50 (PLGA) (26269, Polysciences Inc.) was dissolved in neat chloroform (Merck) at a concentration of $2 \%(\mathrm{w} / \mathrm{v})$. Poly(glycolic acid) (06525, Polysciences Inc.) was dissolved in neat HFIP at a concentration of $1 \%(\mathrm{w} / \mathrm{v})$ and left to stir overnight at room temperature. To encapsulate FITC into the nanoparticles, prior to electrospraying $2 \mathrm{mM}$ of FITC was added to the polymer solutions and mixed thoroughly. The homogeneous polymer solution was introduced into a $10 \mathrm{~mL}$ plastic syringe and a blunt-tip needle attached. Any air bubbles were removed and the filled syringe was fixed in a mechanical syringe pump. All work was carried out at ambient conditions in a fume-hood. To assess initial nanoparticle formation, nanoparticles were sprayed into a glass dish filled with $0.1 \%(\mathrm{v} / \mathrm{v})$ isopropanol (Merck) in $\mathrm{dH}_{2} \mathrm{O}$ placed on a magnetic stirrer, connected to a grounding plate and left to spray for $1 \mathrm{~h}$. Nanoparticles were then decorated on the basal surface of the electrospun membrane using the optimal electrospraying 
parameters. Working parameters for PGA nanoparticles were $25 \mathrm{kV}, 25 \mathrm{~cm}$ working distance, $2 \mathrm{ml} / \mathrm{h}$ flow rate; and for PLGA nanoparticles; $11 \mathrm{kV}, 13 \mathrm{~cm}$ working distance, $0.5 \mathrm{ml}$ flow rate (Supplementary Figure S1).

\section{Fibre and Nanoparticle Diameter Measurements}

Diameter measurements were undertaken to determine fibre/nanoparticle size and homogeneity between fabrication batches. The diameter of 50 fibres and nanoparticles from three different images of the electrospun fibres and electrosprayed nanoparticles were measured using Image $(n=3)$.

\section{Preparation of Fibres and Nanoparticles for SEM}

Scanning electron microscopy (SEM) was undertaken to characterise the morphology of the fibres and nanoparticles. Electrospun membrane or $10 \mu \mathrm{l}$ of electrosprayed nanoparticles suspended in solution was placed on a carbon tab (TAAB) mounted on an aluminium stub (TAAB). The nanoparticles were surrounded by a layer of silver dag (Merck) and were left overnight in a desiccator for the solution to evaporate. Membrane or nanoparticles were gold sputter coated (Quorum) and imaged using SEM (Quanta FEG250 ESEM) with EHT of $5 \mathrm{kV}(n=3)$.

\section{Contact Angle Measurements}

To measure the wettability and identify if membranes were hydrophilic or hydrophobic, WCA measurements were carried out. Electrospun membranes were cut into $3 \mathrm{~cm} \times 1 \mathrm{~cm}$ rectangles. Samples were either untreated, UV treated $(1 \mathrm{~h})$, placed in ethanol, or placed in cell culture medium and left to dry before being measured for changes in wettability using sessiledrop goniometry on the DSA 100 (Kruss-Scientific) $(n=6)$. Briefly, a $5 \mu \mathrm{L}$ water drop is recorded being released from a needle tip onto the membrane. A still is then taken from this video and the contact angle determined using the tangent method. Generally, a WCA smaller than $90^{\circ}$ is considered hydrophilic and a WCA bigger than $90^{\circ}$ is considered hydrophobic.

\section{Tensile Testing}

Mechanical properties of the electrospun membranes were determined using tensile testing. Quantitative tensile testing of the electrospun membrane was undertaken using UniVert tensile tester (CellScale) equipped with a $10 \mathrm{~N}$ load cell at a displacement rate of $12 \mathrm{~mm} / \mathrm{min}$. The membranes were cut into dog-bone shaped strips $2 \mathrm{~cm}$ in length by $0.5 \mathrm{~cm}$ in width and tested until failure or until the tensile tester had reached maximum distance $(n=16)$. Membrane thickness was measured using a digital micrometer (HITEC, 190-00, Farnell). For wet samples $(n=7)$, samples were soaked in $\mathrm{dH}_{2} \mathrm{O}$ before mounting into the tensile tester.

\section{FTIR}

Fourier-transform infrared spectroscopy measurements were undertaken to determine changes in surface chemistry following membrane surface treatment. Electrospun membranes were cut into $3 \mathrm{~cm} \times 1 \mathrm{~cm}$ rectangles. Samples were either untreated, UV treated $(1 \mathrm{~h})$, placed in ethanol, or placed in cell culture medium and left to dry before being measured using Vertex 70 Fourier Transform Infrared Spectrometer (Vertex) $(n=6)$.

\section{Cell Culture}

Electrospun membrane was cut into $1.5 \mathrm{~cm}^{2}$ squares and placed in Scaffdex (Merck). ARPE-19 cells (ATCC-LGC, CRL2302 passage 28-30) were seeded at a density of 50,000 cells/sample and incubated at $37^{\circ} \mathrm{C}, 5 \% \mathrm{CO}_{2}, 98-99 \%$ humidity and grown for 1 month or 3 months. Media consisted of DMEM:F12 (Merck) containing $10 \%$ FCS (Thermofisher Scientific), $2.5 \mathrm{mg} / \mathrm{L}$ amphotericin B (Merck) and penicillinstreptomycin (Merck). Media was changed every 3 days. Controls were glass coverslips (Agar).

For long-term culture, the membrane was fabricated as aforementioned and then mounted onto a grounded water bath as described. Nanoparticles were sprayed onto the membrane using the described parameters followed by cutting and mounting into Scaffdex with the nanoparticle decorated side orientated to be the basal side. Cells were seeded onto the apical side and cultured as mentioned above.

\section{Histology}

We used histology to determine whether the cells had invaded across the thickness of the membrane. It is important the cells do not invade the entire membrane and culture only on the surface of the membrane. Cell cultured membranes were fixed in 10 $\% \mathrm{NBF}$ for $15 \mathrm{~min}$ and processed for histological staining with Leica TP1020. Following processing, tissues were embedded for sectioning in paraffin wax and stained with Haemotoxylin and Eosin ( $\mathrm{H} \& \mathrm{E})$ using standard protocol, images were taken with Olympus BX60 microscope, 20x objective, no post-processing $(n=4)$.

\section{Preparation of Cells for SEM}

Scanning electron microscopy was used to visualise membrane coverage and cell morphology following cell culture. Cells were fixed in $1.5 \%$ Glutaraldehyde (Fluka) for $30 \mathrm{~min}$ at $4^{\circ} \mathrm{C}$ and dehydrated with graded ethanol; $2 \times 3 \mathrm{~min} 50 \%, 2 \times 3 \mathrm{~min}$ $70 \%, 2 \times 3 \mathrm{~min}$ at $90 \%, 2 \times 5 \mathrm{~min}$ at $100 \%$. Hexamethyldisilane (HMDS, Merck) was added for $2 \times 5$ min and left overnight to evaporate. Samples were mounted on a carbon tab on an aluminium stub, gold sputter coated (Quorum) and imaged using SEM (Quanta FEG250 ESEM) with EHT of $5 \mathrm{kV}(n=3)$.

\section{Immunofluorescence Staining}

To visualise the presence of RPE characteristic proteins in the ARPE-19 cells cultured on electrospun membranes, we carried out immunofluorescence studies. Cell cultured membranes were harvested after 1 or 3 months of culture, washed with DPBS and fixed in $10 \% \mathrm{NBF}$ for 15 min. Cells were permeabilised with $1 \%$ Triton-X for $10 \mathrm{~min}$, blocked with $10 \%$ goat serum for $30 \mathrm{~min}$ and incubated with primary antibodies (Table 1) overnight at $4 \mathrm{C}$. The following day, cells were incubated with the appropriate secondary antibody for $1 \mathrm{~h}$, followed by DAPI staining, and membrane placed on glass slides and mounted to coverslips with Vectorshield (Vectorlabs). Slides were viewed using the Zeiss 
TABLE 1 | Primary antibody stains and the companies from where they were bought with corresponding catalogue numbers.

\begin{tabular}{ll}
\hline Primary antibody & Company (catalogue number) \\
\hline Anti-Bestrophin/BEST1 antibody & Abcam (ab14927) \\
Anti-RPE65 antibody & Abcam (ab13826) \\
Anti-LRAT antibody & Abcam (ab166784) \\
Anti-PEDF antibody & Abcam (ab180711) \\
Anti-CRABP1 antibody & Abcam (ab235838) \\
Anti-MERTK antibody & Abcam (ab110108) \\
Anti-LAMP2 antibody [H4B4] & Abcam (ab25631) \\
Anti-USO1 antibody & Abcam (ab102470) \\
Anti-GULP antibody & Abcam (ab236893) \\
ZO-1 & Thermofisher Scientific (61-7300) \\
Alexa Fluor 488 Phalloidin & Thermofisher Scientific (A12379) \\
\hline
\end{tabular}

ImagerM1 microscope, numerical aperture of x10 objective 0.2 , Nikon camera, no post-processing $(n=3)$.

\section{Resazurin Assay}

To assess metabolism of cells cultured on the surface of the membranes, we used a resazurin cell metabolism assay. In this assay, resazurin (an oxidised non-fluorescent blue colored compound) is reduced by metabolically active cells to resorufin (a fluorescent pink product), which is detected via fluorescence measurement. Resazurin solution (5 mg resazurin salt in $40 \mathrm{~mL}$ DPBS) (PAA laboratories), was added to each sample $(100 \mu \mathrm{l} / \mathrm{ml})$ and returned to the incubator for $4 \mathrm{~h}$. A $100 \mu \mathrm{l}$ aliquot of media was taken from each sample and transferred into a black bottomed 96-well plate. Fluorescence was measured at 530-510 nm excitation and $590 \mathrm{~nm}$ emission using a fluorescence reader (FLUOstar OPTIMA, BMG LABTECH) $(n=4)$.

\section{Barrier Assay}

To assess the ability of the membrane to act as a barrier, we set up a barrier assay using FITC as the detectable dye to traverse the membrane on both a cellular and cell cultured membranes (Yeste et al., 2018). Scaffdex mounted membranes, with or without cells, were placed in 12 well plates with DPBS on the basal side of the membranes. On the apical side of the membranes, $1 \mathrm{mM}$ FITC (Merck) in DPBS was added. Every $10 \mathrm{~min}, 100 \mu \mathrm{l}$ of DPBS was taken from the basal side of the membranes and measured using the fluorescence reader (FLUOstar OPTIMA, BMG LABTECH) $(n=4)$.

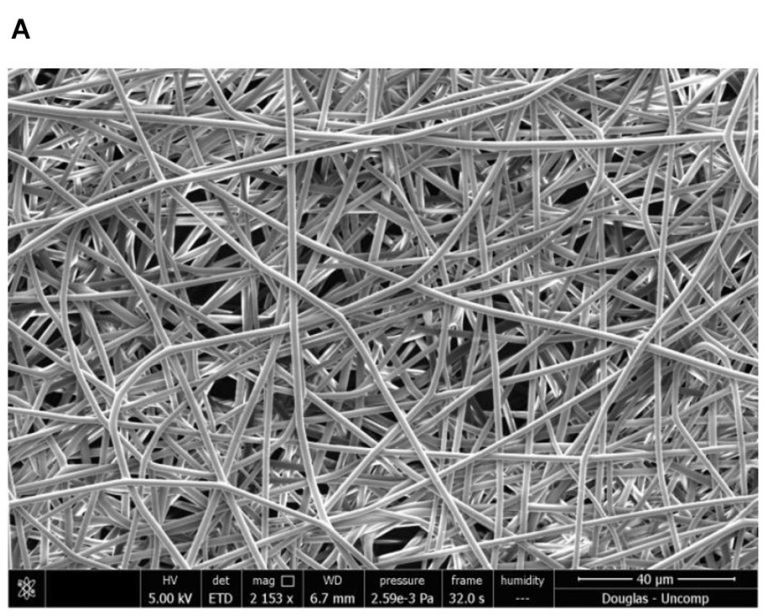

B
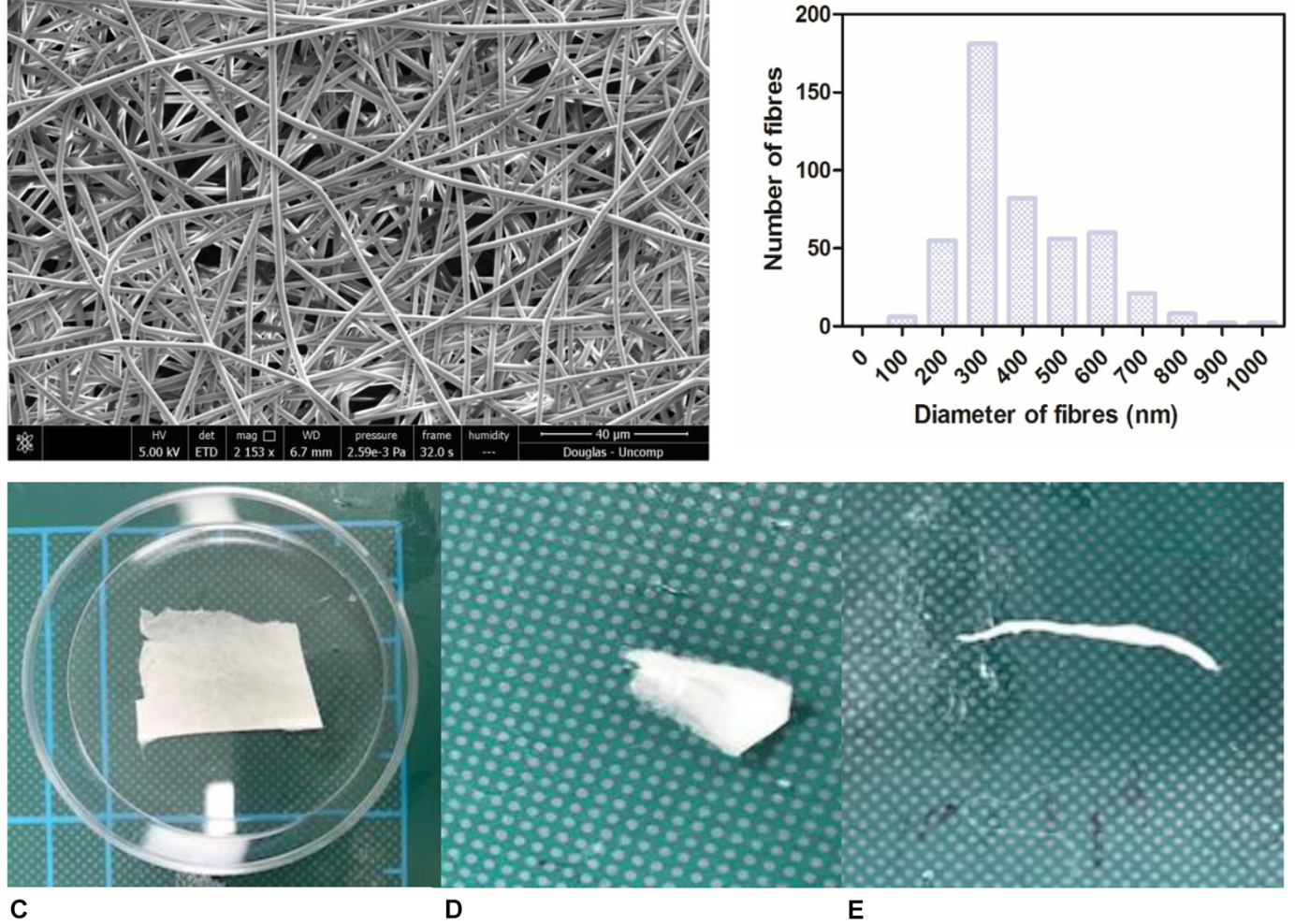

FIGURE 1 | SEM micrograph of $17.5 \%$ PET electrospun membrane exhibiting ultrastructure of randomly orientated fibres (A) and corresponding histogram showing distribution of fibre diameter size; average diameter of $387 \mathrm{~nm}(+/-6.9)$ (B). Photographs of material folded (C), rolled (D), twisted (E) without breaking denote good handleability of the material $(n=3)$. Scale shown $=5 \mathrm{~cm}$. 


\section{Live/Dead Assay}

Live/dead assays were undertaken to visualise the viability of cells grown on the membranes following culture with and without nanoparticles to assess the effect the presence of degrading nanoparticles had on the cells. Cell cultured membranes were washed in DPBS and following manufacturer's instructions (molecular probes) incubated with calcein AM and ethidium homodimer-1 for $30 \mathrm{~min}$. The material was placed on glass slides and mounted to coverslips with Vectorshield (Vectorlabs). Slides were viewed using the Zeiss ImagerM1 microscope, $\mathrm{x} 4$ objective, Nikon camera, no post-processing $(n=3)$.

\section{pH Measurements}

Three $\mathrm{pH}$ measurements were taken from each well using a digital $\mathrm{pH}$ meter to assess if broad changes in $\mathrm{pH}$ due to nanoparticle degradation over time occurred that could affect cell viability (Mettler-Toledo) $(n=6)$.

\section{Measurement of FITC Dye Release}

Release of encapsulated FITC dye from the nanoparticles with time was assessed to determine how long the encapsulated moieties could be sustainably released. Following electrospraying, $10 \mathrm{ml}$ of collected nanoparticles in $0.1 \%(\mathrm{v} / \mathrm{v})$ isopropanol was kept at $37^{\circ} \mathrm{C}$. An aliquot $(1 \mathrm{ml})$ of solution was then collected at each time point and kept at $-20^{\circ} \mathrm{C}$ until the final time point. For collection from cell cultures $1 \mathrm{ml}$ of media was collected at each time point and media changed. A $100 \mu \mathrm{l}$ aliquot was taken from each sample and transferred into a black bottomed 96well plate. Fluorescence was measured at 530-510 nm excitation and $590 \mathrm{~nm}$ emission using a fluorescence reader (FLUOstar OPTIMA, BMG LABTECH) $(n=4)$.

\section{Statistical Analysis}

Data are presented as mean (+/ - standard error) with $n$ values noted within the text. Analysis was undertaken using GraphPad Prism software using $t$-tests or one-way ANOVA followed by the appropriate post-test noted within the text. Significance was $p<0.05$.

\section{RESULTS AND DISCUSSION}

\section{Characterisation of Electrospun PET: Morphology, FTIR, Hydrophilicity, Mechanical Properties, Barrier Assay, and Cell Culture}

Scaffolds were characterized for adequate mechanical properties to undergo surgical handling and the ultrastructure was
A

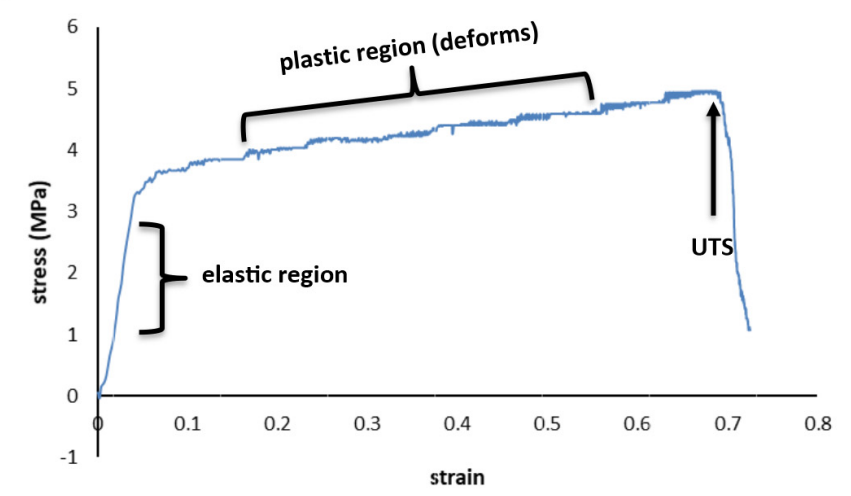

B

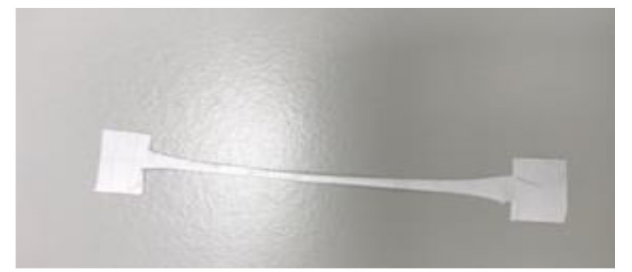

C

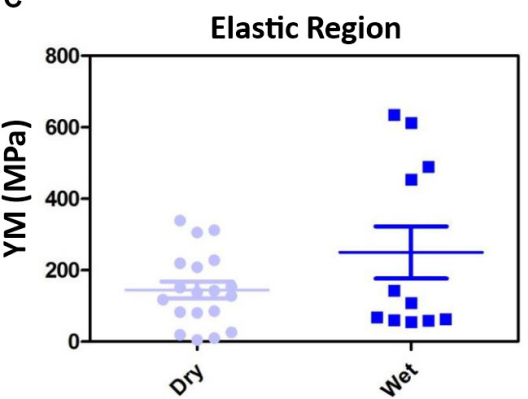

D

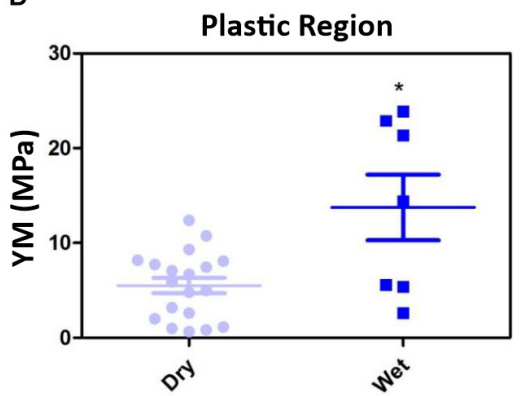

E

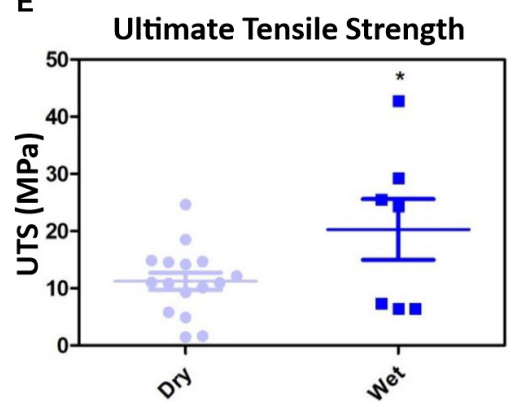

FIGURE 2 | The membranes gave an interesting stress vs. strain plot, as shown by the representative profile (A) and stretched to deformation (B). Young's modulus (YM) for the elastic region (retains form) are high, with no significant difference between the dry [145.2 MPa $(+/-23.46)]$ and wet $(250.2 \mathrm{MPa}(+/-73.08)$ membranes (C), whereas the plastic region (deformation) YM significantly increased from $5.15 \mathrm{MPa}(+/-0.82)$ (dry) to $13.75 \mathrm{MPa}$ (+/-3.47) (wet) (D), and the ultimate tensile strength (UTS) of the membrane significantly increased from $11.23 \mathrm{MPa}(+/-1.5)$ (dry) to $20.29 \mathrm{MPa}(+/-5.3)$ (wet) (E). Significant difference ${ }^{*} p<0.05$ compared with dry material, $t$-test $(n=16$ for $d r y, n=7$ for wet). Data presented: mean $(+/-$ standard error). 
characterized to match fibre morphology to mimic the native BM (Yamamoto and Yamashita, 1989; Del Priore et al., 2006). Surface chemistry was analyzed for presence of functional groups following surface treatment and hydrophilic properties measured using WCA. Barrier properties were analyzed with and without a monolayer of cells to ascertain any changes with cell culture.

Nanofibrous non-degradable PET fibres were produced in a collectable membrane form. SEM micrographs showed the
A

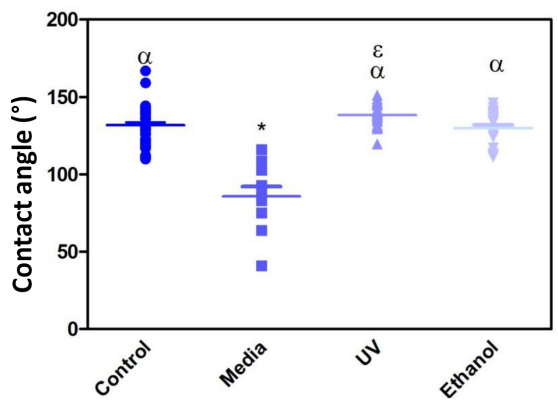

B

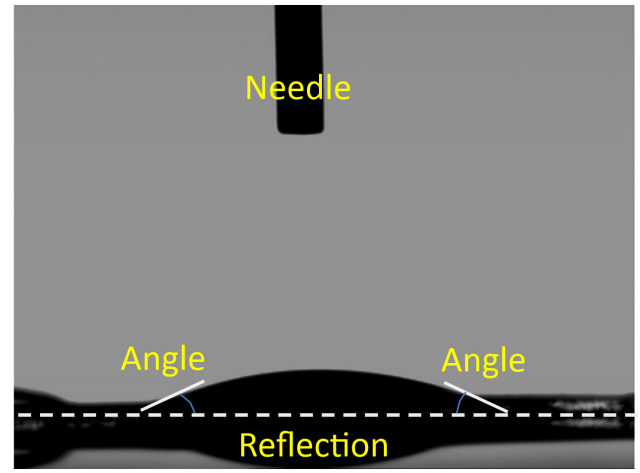

FIGURE 3 | (A) Shows a dot-plot exhibiting the WCA of PET untreated control, cell culture media treated, UV treated and ethanol treated membranes. Media treated membrane exhibited a significantly different decrease in WCA $\left(85.8^{\circ}+/-20\right)$ compared to control and all other treatments. One-way ANOVA followed by Tukey's post hoc test $(n=6)$. ${ }^{*} p<0.05$ significantly different to untreated control, $\alpha=p<0.05$ significantly different to cell culture media treated, $\varepsilon=p<0.05$ significantly different to ethanol treated. Data presented: mean (+/- standard error). (B) shows the image taken of a water drop on top of the membrane, the flat droplet morphology shows the membrane is hydrophilic (note the white dashed line is the contact surface).

A

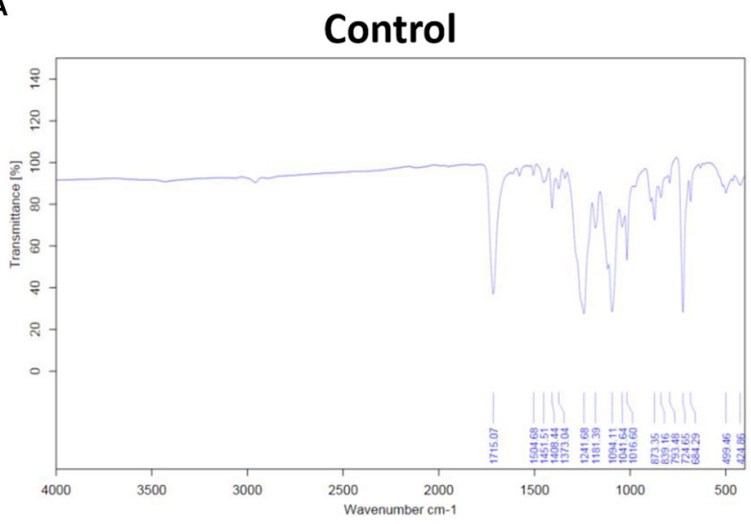

C

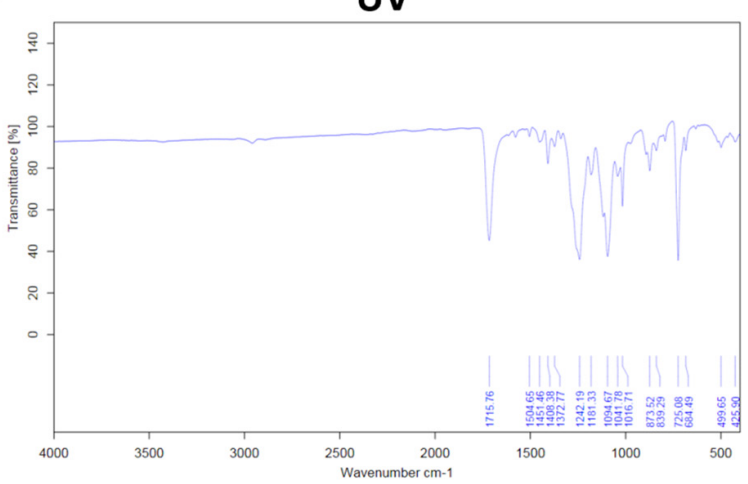

B

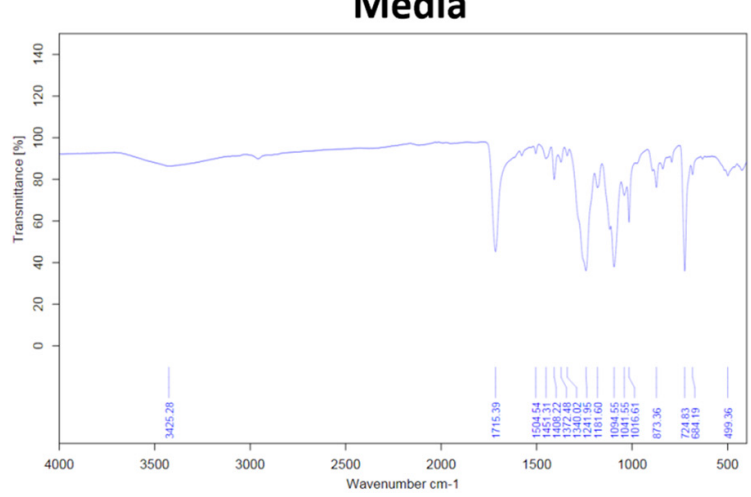

D

Ethanol

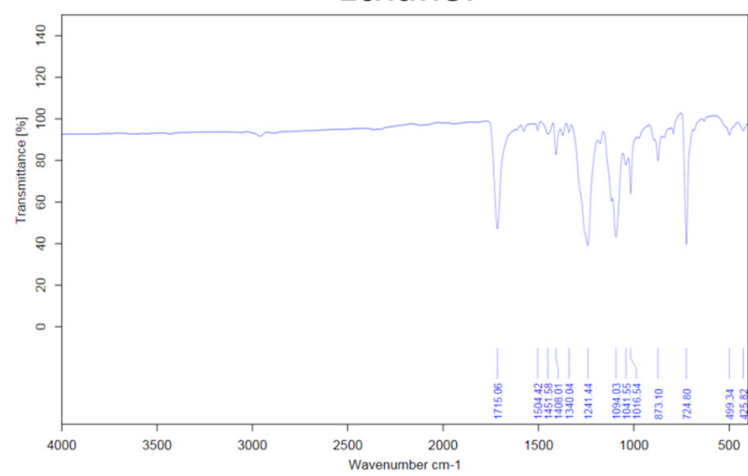

FIGURE 4 | (A) Shows the FTIR spectra of electrospun membrane untreated control, (B) shows the FTIR spectra of tissue culture media treated membrane, (C) shows the FTIR of ethanol treated membrane, and (D) shows the FTIR of the UV treated membrane. All spectra exhibit the characteristic PET carbonyl peak at $\sim 1700 \mathrm{~cm}^{-1}$ with the media treated membrane exhibiting a peak at $\sim 3400 \mathrm{~cm}^{-1}$ suggesting evidence of protein interaction $(n=6)$. 


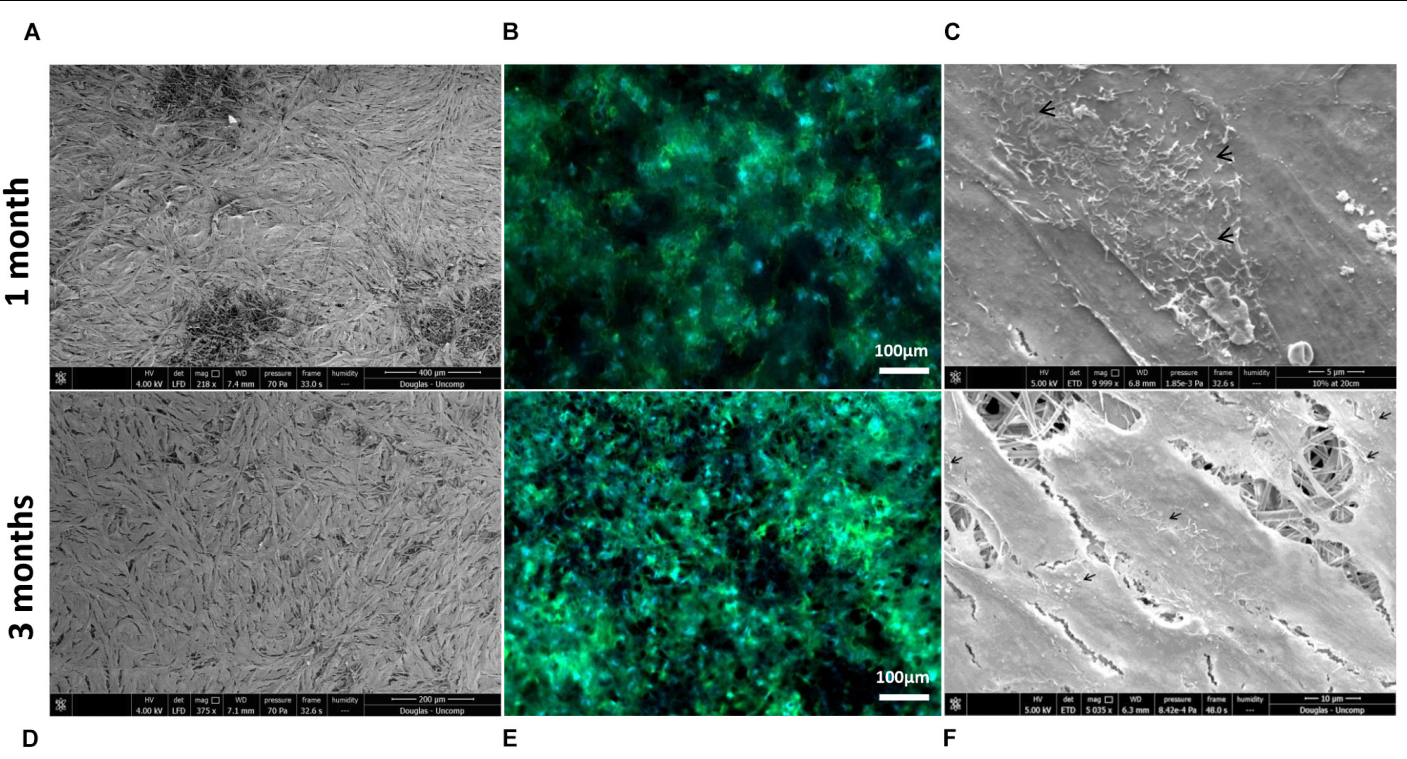

FIGURE 5 | Representative SEM micrographs and corresponding fluorescence images of DAPI/phalloidin stained ARPE-19 cells cultured on PET membranes for 1 month (A-C) and 3 months (D-F). Cells populate the membrane with better coverage and more apparent phalloidin staining at 3 months culture. Microvilli (arrows) phenotypical of RPE cells are apparent by 1 month $(n=3)$.
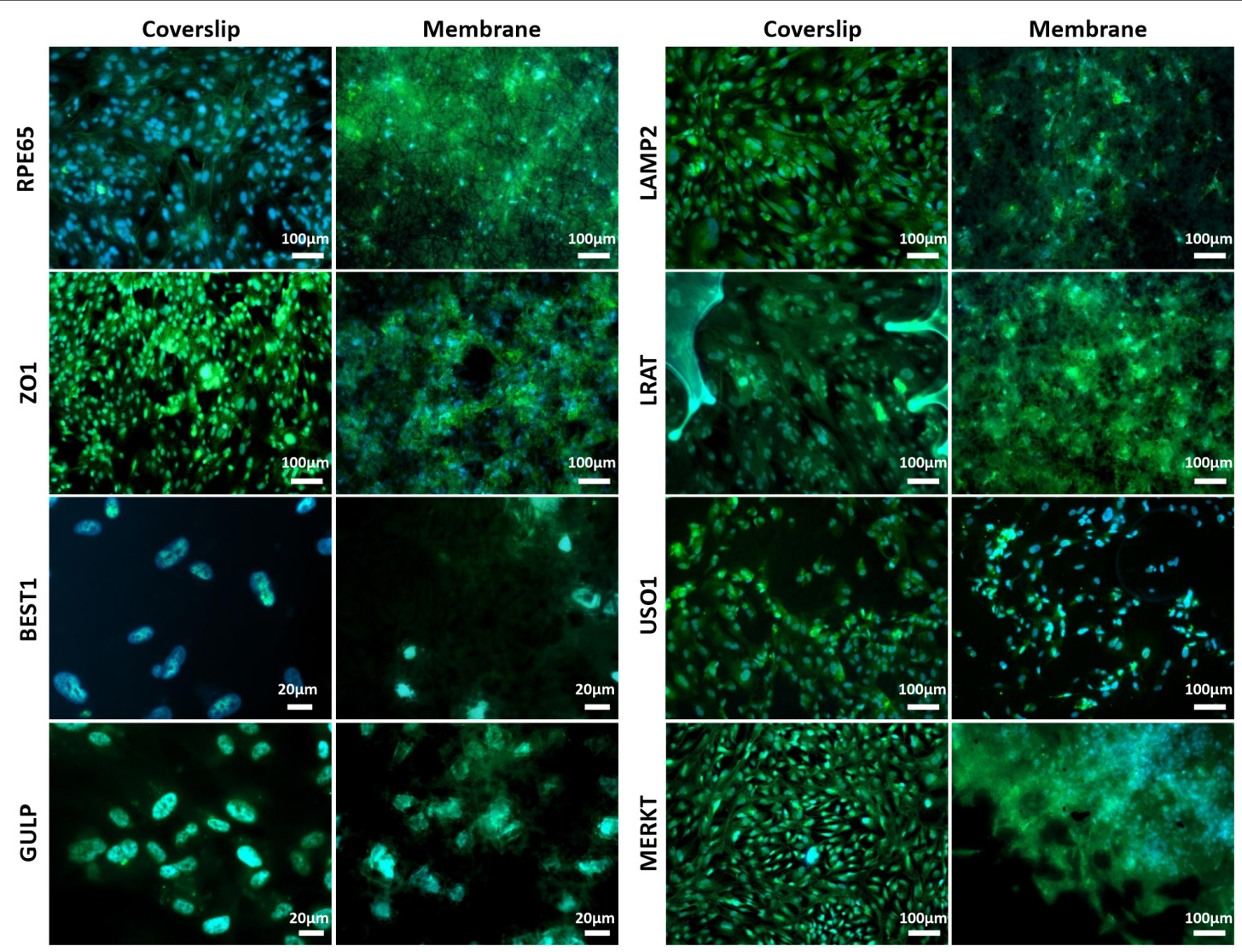

FIGURE 6 | Representative immunofluorescent images show RPE cells cultured on the electrospun membrane for 1 month stained positively for RPE cell marker proteins and RPE function proteins (green). Cells cultured on the membranes were difficult to image clearly due to the auto-fluorescent nature of the PET fibres. Upon comparison with the positive glass coverslip control, similar staining patterns are apparent, especially noticeable with BEST1, GULP and USO1. DAPI = blue nuclear stain $(n=3)$. 
A

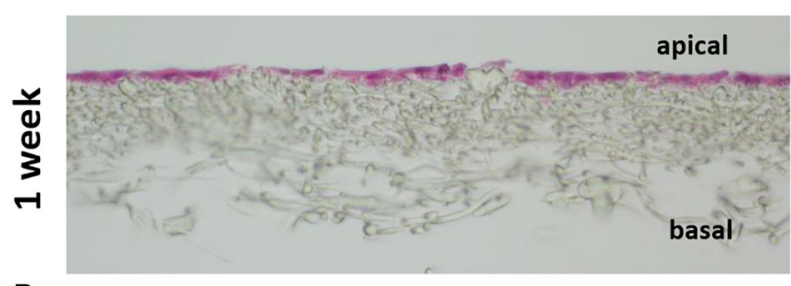

B

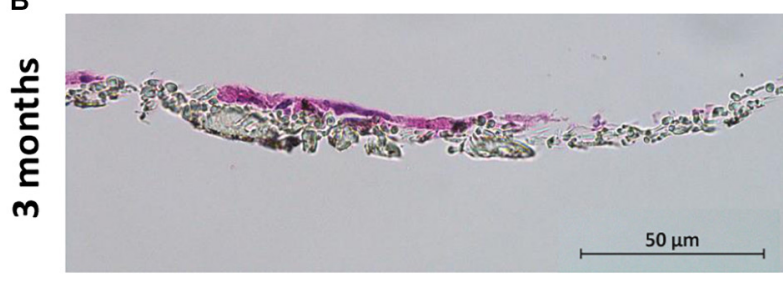

C basal surface after 3 months' ARPE19 culture on apical surface

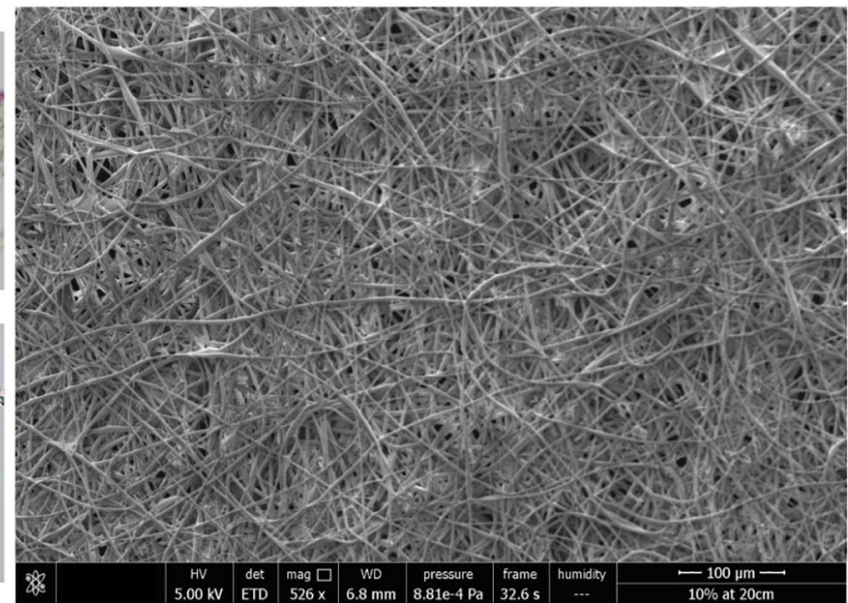

FIGURE 7 | The membrane does not allow invasion of cells through its architecture. H\&E staining of cells cultured on the membrane for 1 week (A) up to 3 months (B) show the desired lack of cell invasion. The SEM micrograph (C) exhibits a lack of cells on the basal side of the membrane that had been seeded with ARPE-19 cells on its apical side and cultured for 3 months $(n=4)$.

membranes exhibited a randomly orientated fibrous mesh (Figure 1A); an open network of interconnected voids with average fibre diameter of $387 \mathrm{~nm}(+/-147.8)$ (Figure 1B). The membrane was able to undergo folding, rolling, and twisting without being destroyed; depicting the ease with which it could be handled and exhibiting adequate mechanical properties (Figures 1C-E). The handling properties were in agreement with previously published work, even though the concentration of the polymer solution used was lower than previous work (Haneef and Downes, 2015). Morphologically this electrospun membrane mimics native BM (Yamamoto and Yamashita, 1989) and electrospun PET has previously been reported to exhibit tolerance to subretinal insertion with a lack of inflammatory response (Liu et al., 2014).

The membrane gave an interesting stress vs. strain profile following tensile testing; exhibiting an elastic region (original form is retained following release of load) and a plastic region (membrane deforms indefinitely) before attaining failure exhibiting the UTS (Figures 2A,B). 16\% of membranes tested did not break (Supplementary Figure S2). Soaking the membranes in $\mathrm{dH}_{2} \mathrm{O}$ did not significantly change the $\mathrm{YM}$ of the elastic region (Figure 2C), however, the YM of the plastic region significantly increased from 5.5 $\mathrm{MPa}(+/-0.8)$ to $13.8 \mathrm{MPa}(+/-3.5)$ and the UTS significantly increased from an average of $11.23 \mathrm{MPa}$ $(+/-1.5)$ to $20.29 \mathrm{MPa}(+/-5.3)$ (Figures 2D,E). Wetting the membrane introduced hydrogen bonding between the fibres thereby increasing the YM of the plastic region and the UTS, while in the dry form the fibres did not have the water to provide the added interactions (Chen et al., 2018; Kurokawa et al., 2018).

Treatment of the membrane with cell culture media significantly increased hydrophilicity compared to all other treatment methods, whereas ethanol treatment resulted in an increase in the hydrophilicity compared only to UV treatment.
WCA of control membranes averaged at $132.6^{\circ}$ which decreased to $85.8^{\circ}$ and $118.4^{\circ}$ following treatment with media and ethanol, respectively (Figures 3A,B and Supplementary Table S1). FTIR spectra exhibit the characteristic carbonyl peak in PET membrane typical of the ester bond group within the polymer structure, denoted by the strong peak at $\sim 1700 \mathrm{~cm}^{-1}$ for $\mathrm{C}=\mathrm{O}$. No changes were detected for any of the membranes except the cell culture media treated membrane. A peak at $\sim 3400 \mathrm{~cm}^{-1}$ denoting the presence of $\mathrm{O}-\mathrm{H}$ group was detected, suggesting that the

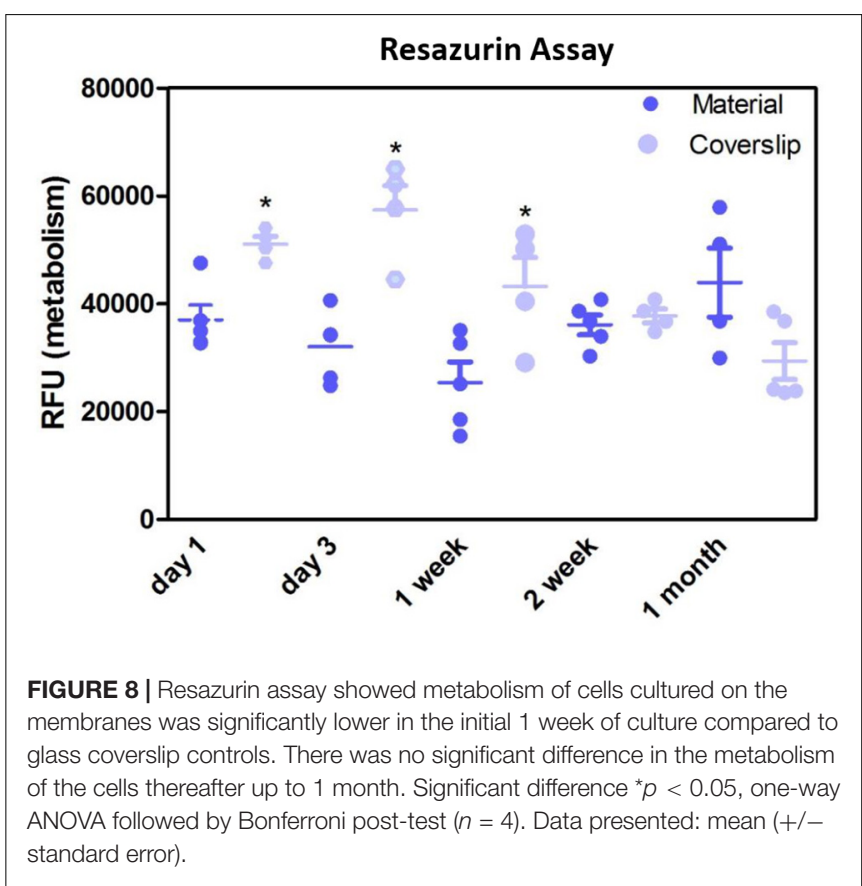


surface of the membrane underwent a degree of functional group opening to form - $\mathrm{COOH}$ free groups that could be attributed to protein interaction or hydrolysis of the surface of the polymer (Figures 4A-D; Haneef and Downes, 2015; Kawai et al., 2019).

Scanning electron microscopy and phalloidin staining showed cells were able to form a monolayer when cultured on the membrane up to 3 months, with microvilli that are phenotypical of RPE cells (Thomson et al., 2011) presenting after 1-month's culture (Figures 5A-F). Although the auto-fluorescence of the membrane fibres made it challenging to see clearly, cells plated on the membrane stained positively for the characteristic proteins of RPE cells (Liao et al., 2010; Brandl et al., 2014) in comparison with
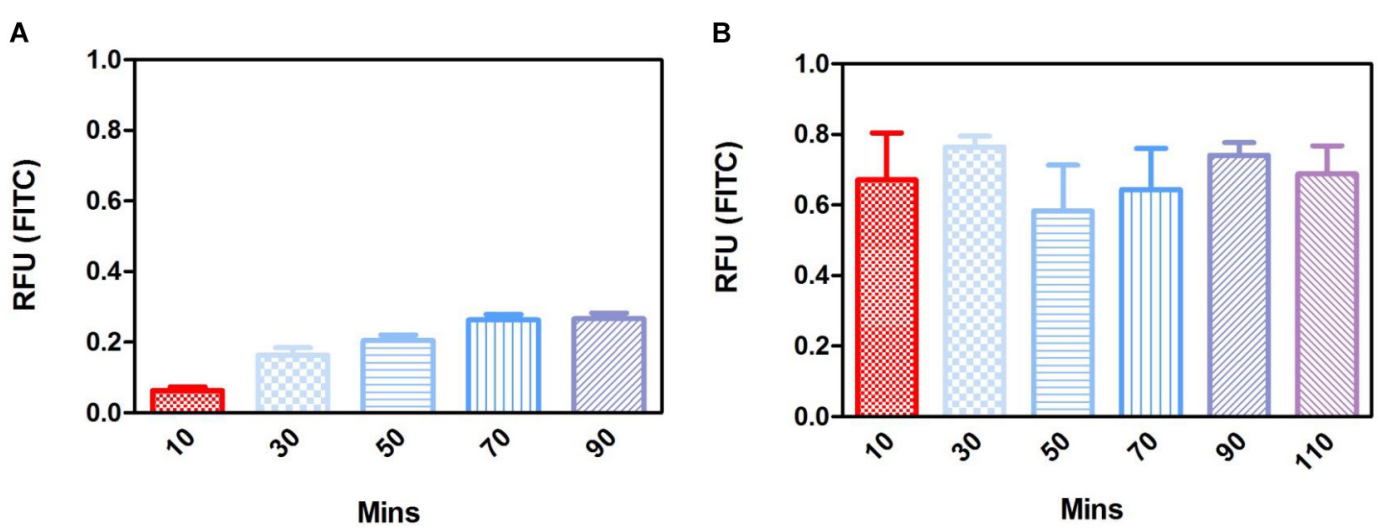

FIGURE 9 | Fluorescence barrier assays in the acellular substrate showed passive diffusion that plateaued FITC concentration across the membrane by 70 min (A), whereas fluorescence in the 1-month cell cultured membrane plateaued in the first 10 min of measurement suggesting the active transport of FITC by the monolayer of cells $\mathbf{( B )}(n=4)$. Data presented: mean (+/- standard error).

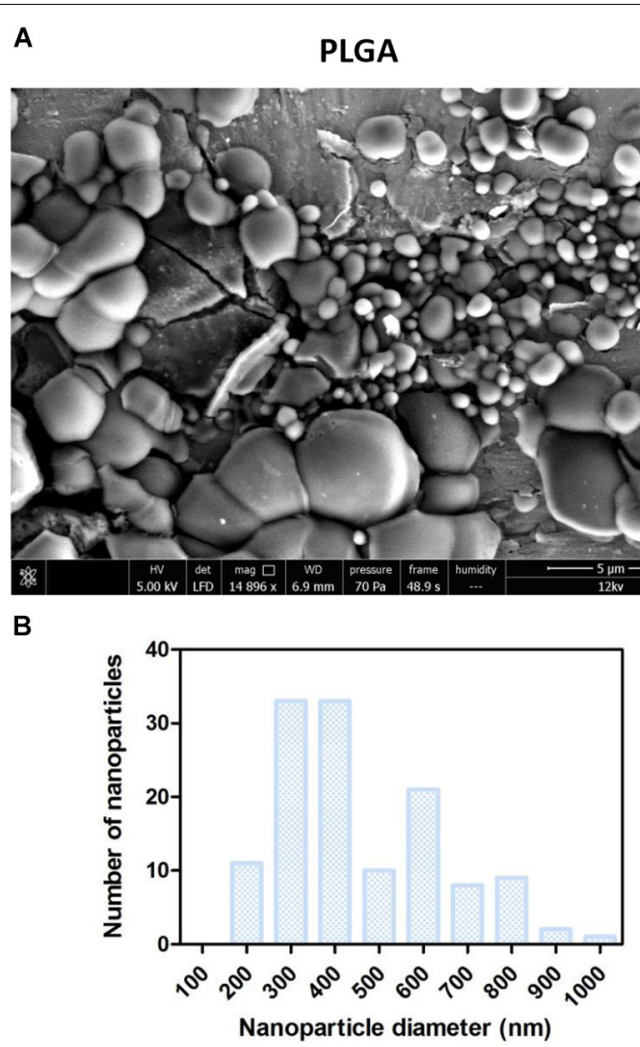

C

PGA

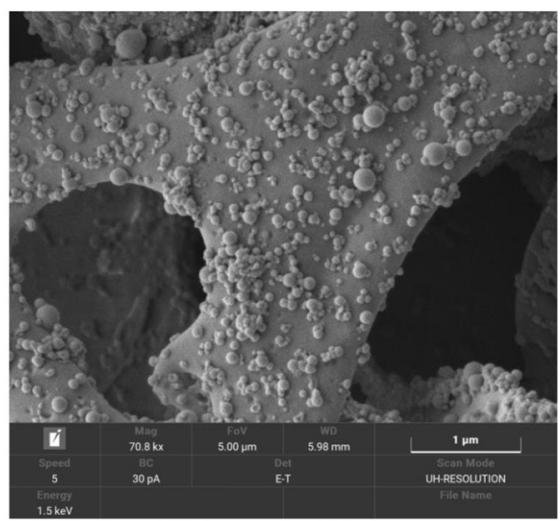

D

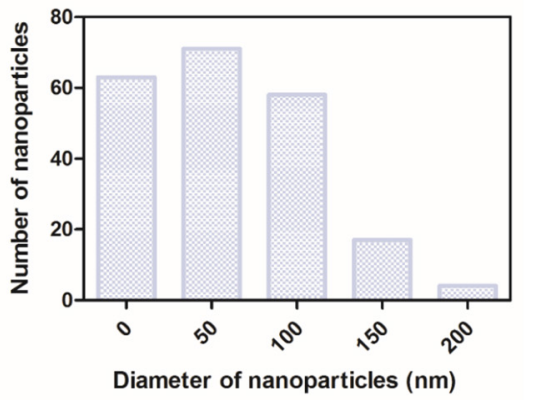

FIGURE 10 | SEM micrographs show PLGA nanoparticles (A,B) were larger than PGA nanoparticles (C,D) Corresponding histograms showed PLGA averaged at $480 \mathrm{~nm}(+/-252)$ with a broader range of particle sizes, whereas PGA averaged at $59 \mathrm{~nm}(+/-49)$ and exhibited less variation in particle size $(n=3)$. Data presented: mean (+/- standard error). 
positive controls (Figure 6). This is particularly noticeable with BEST1 (bestrophin-1), a $\mathrm{Ca}^{2+}$-activated $\mathrm{Cl}^{-}$channel (CaCC) specifically expressed in the RPE of the eye (Kittredge et al., 2018), USO1 (General vesicular transport factor p115) and GULP (PTB domain-containing engulfment adaptor protein 1), an adaptor protein involved in phagocytosis (Park et al., 2008), an important function of RPE with involvement in the phagocytosis of photoreceptor outer segments (Sparrow et al., 2010).

$\mathrm{H} \& \mathrm{E}$ stained sections showed the lack of cell invasion in the bulk structure of the membrane, which was the desired characteristic at both 1 week and 3 months' culture (although some material loss was seen due to the histological processing method in month 3) (Figures 7A,B). This was further confirmed with SEM imaging showing the absence of any cells on the basal side of the membrane following cell culture on the apical side (Figure 7C).

Resazurin assays showed the metabolism of the cells cultured on the membrane was significantly lower compared to positive control in the initial first week of culture, thereafter, the metabolism was not significantly different to the positive control (Figure 8). This may have been due to cells not adhering as quickly due to the porosity of the membrane, as this difference in metabolism was overcome by 2 weeks. These data are in contrast to previous studies by our group that have shown RPE cells had increased metabolism when plated on an electrospun PET membrane (Haneef and Downes, 2015), however, the membrane formed in the previous study was electrospun for $1 \mathrm{~h}$ and had thinner fibres, giving the membrane a different morphology. Current results, as well as previously published work demonstrating adequate TEER measurements (Haneef and Downes, 2015) show that ARPE-19 cells were able to form a monolayer, express proteins and exhibit microvilli phenotypical to the RPE cells, after long-term culture on the current electrospun membrane.

To determine the permeability of the membrane a barrier assay was carried out on acellular membranes and on membranes cultured with ARPE-19 cells for 1 month, as this was when a monolayer had formed. The barrier assay on acellular membranes

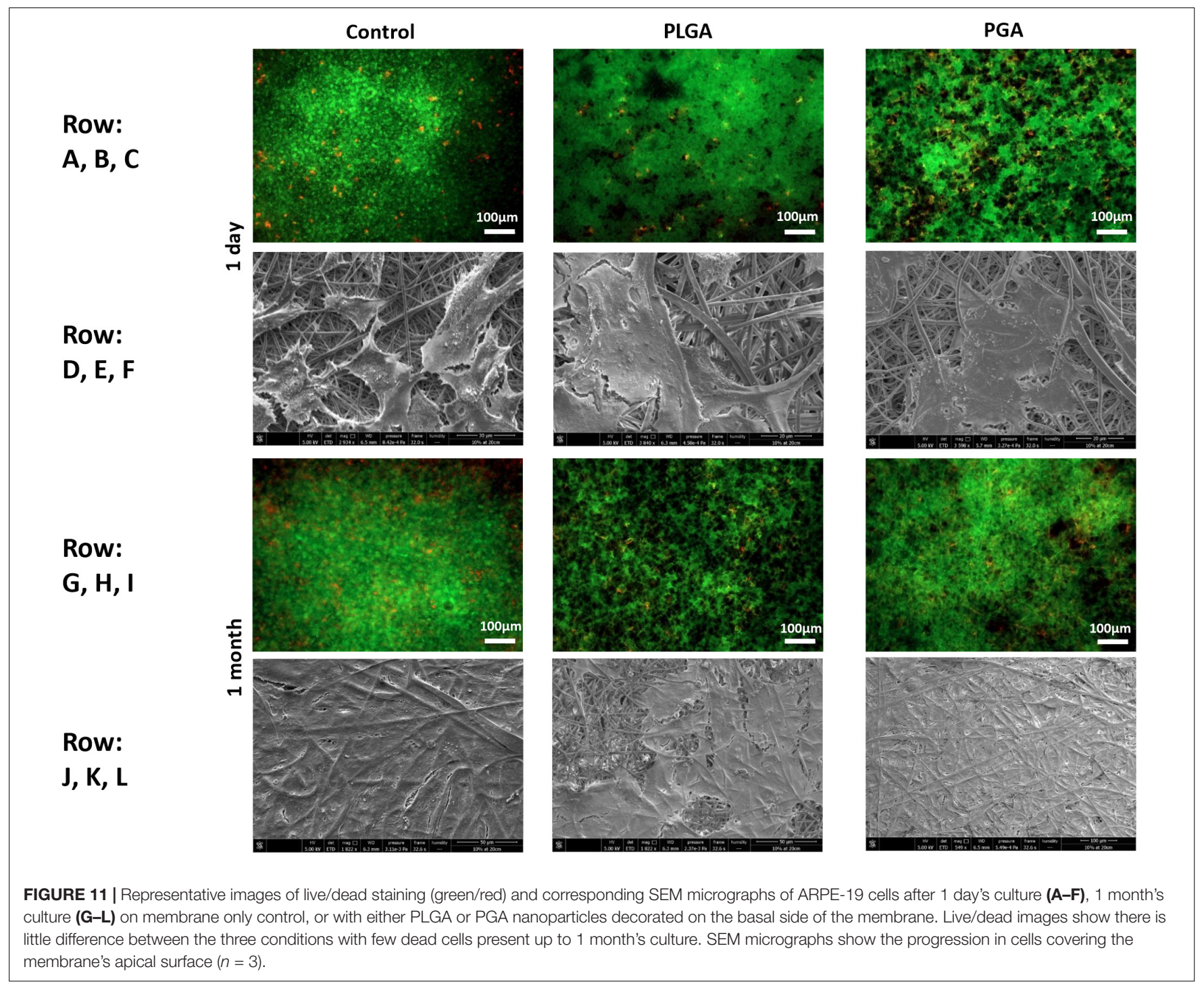


showed FITC was able to passively diffuse through the membrane in a time dependent manner, taking $80 \mathrm{~min}$ for maximum signal to be detected (Figure 9A). Cell cultured membranes showed the transport of FITC had increased with fluorescence plateauing within the first $10 \mathrm{~min}$ of culture, suggesting the monolayer of cells may be actively transporting the FITC across the membrane and functioning correctly (Figure 9B). These data showed that cells plated on the material did not affect the permeability of the membrane and shows it has the appropriate properties to act as an artificial BM.

Future experiments to confirm the ability of the RPE cells to perform phagocytosis when seeded on the PET membrane are needed. The presence of the phagocytosis marker MERKT in the ARPE-19 cells cultured on the PET membrane (Figure 6) suggested the cells had phagocytic potential. Furthermore, a study by da Cruz et al. (2018) have shown the ability of human embryonic RPE cells plated onto a PET membrane to phagocytose both in vitro and following surgical implantation.

\section{Nanoparticles}

Spherical nanoparticles were successfully fabricated with average nanoparticle diameters at $480 \mathrm{~nm}(+/-252)$ for PLGA and $59 \mathrm{~nm}$ (+/-49) for PGA (Figures 10A-D). Interestingly less variation in particle size was seen in PGA particles.

The nanoparticles did not affect ARPE-19 cell viability or morphology when compared with the membrane only control (Figure 11); cells attached $24 \mathrm{~h}$ following seeding and formed a monolayer by 1 month in the presence of nanoparticles. Resazurin assays showed the presence of nanoparticles induced a significant increase in cell metabolism compared to the membrane only control up to 2 weeks, which resolved thereafter up to 1 in month in culture (Figure 12). The increase in metabolism may be attributed to the change in $\mathrm{pH}$ as the nanoparticles degrade with time; it was found that the $\mathrm{pH}$ of the culture media decreased after 1 week for both PLGA and

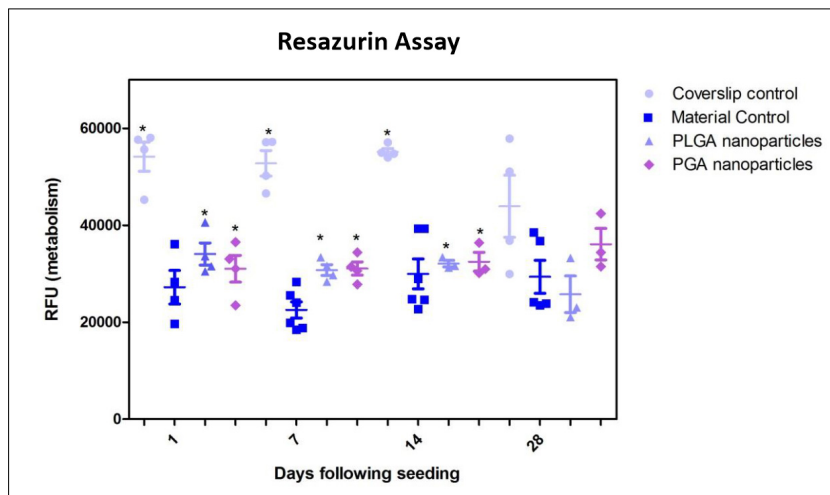

FIGURE 12 | Resazurin assay of ARPE-19 cells plated on membranes with PLGA or PGA nanoparticles decorated on the basal side showed significantly higher metabolism compared to membrane only controls for the first 14 days of culture. There was no significant difference in metabolism of the cells thereafter up to 1 month or compared with coverslip control. Significant difference ${ }^{*} p<0.05$ compared with membrane control, one-way ANOVA followed by Bonferroni post-test $(n=4)$. Data presented: mean $(+/-$ standard error).

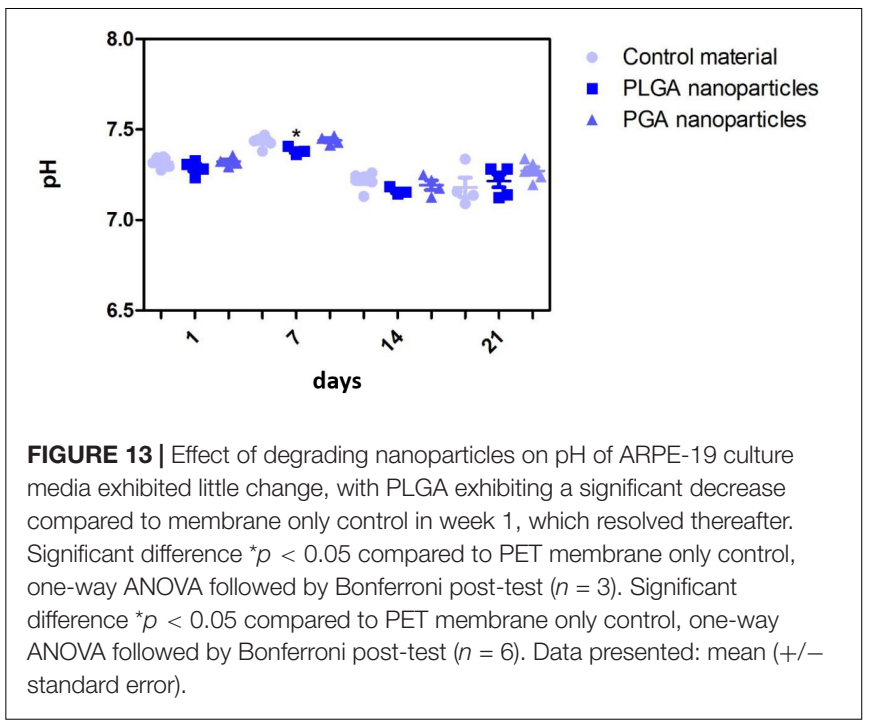

PGA nanoparticles (Figure 13 and Supplementary Table S2). PLGA nanoparticles significantly decreased the $\mathrm{pH}$ up to 1 week's degradation compared to membrane only control. The metabolites of PLGA degradation are lactic acid and glycolic acid, which contribute to lowering the $\mathrm{pH}$ of the surrounding environment. It could also be attributed to the larger variation in particle size which could be contributing to the significant change in $\mathrm{pH}$ compared to PGA.

Although a difference in metabolism of cells and $\mathrm{pH}$ of their surrounding environment was observed when cultured with nanoparticles; morphology and protein expression results suggest that the cells were not adversely affected by the membrane/nanoparticle composite.

\section{Nanoparticle Degradation and FITC Release Profile}

Short term degradation studies show that over $72 \mathrm{~h}$, both PLGA and PGA nanoparticles degraded releasing FITC into solution ( $0.1 \%$ isopropanol in $\mathrm{dH}_{2} \mathrm{O}$ ). PLGA nanoparticles exhibited a continuous release profile up to $72 \mathrm{~h}$ (Figure 14A) compared to the PGA nanoparticles, which exhibited sudden burst release of the dye after $3 \mathrm{~h}$, which plateaued after $24 \mathrm{~h}$ (Figure 14B).

Long term (up to 28 days) degradation studies showed similar results as the short-term studies with PLGA nanoparticles continuing to sustainably release FITC into solution up to 14 days, decreasing thereafter (Figure 14C). PGA nanoparticles exhibited maximum release after 1 day, but exhibited considerable decrease in FITC release by day 7 onward (Figure 14D). This can be attributed to the faster degradation rate of PGA compared to PLGA and also to the higher surface area:volume ratio of significantly smaller nanoparticles of PGA, which would allow faster release of the dye, due to shorter diffusion pathway and faster degradation (Sharma et al., 2016). Observation of the resultant solution after 28 days degradation would suggest PLGA nanoparticles had released more FITC compared to PGA nanoparticles (Supplementary Figure S3), however, this could also be attributed to more 
A

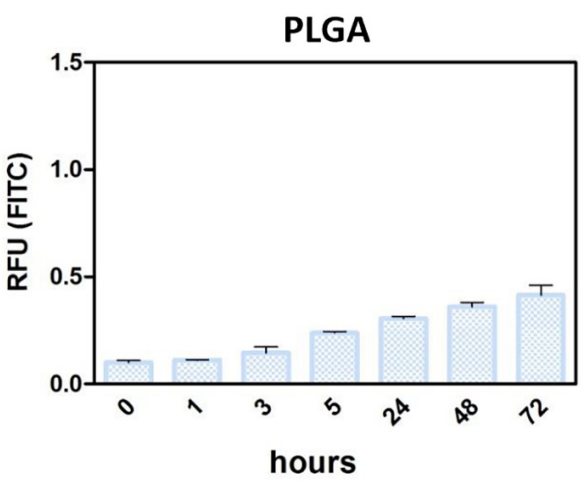

C

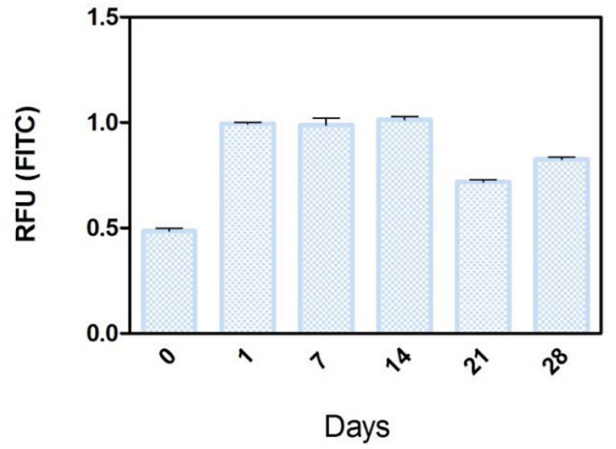

E

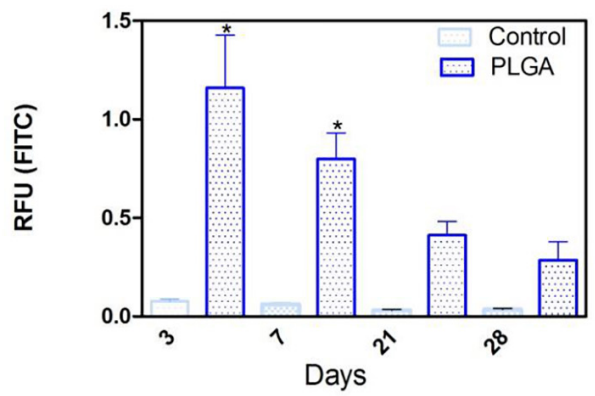

B
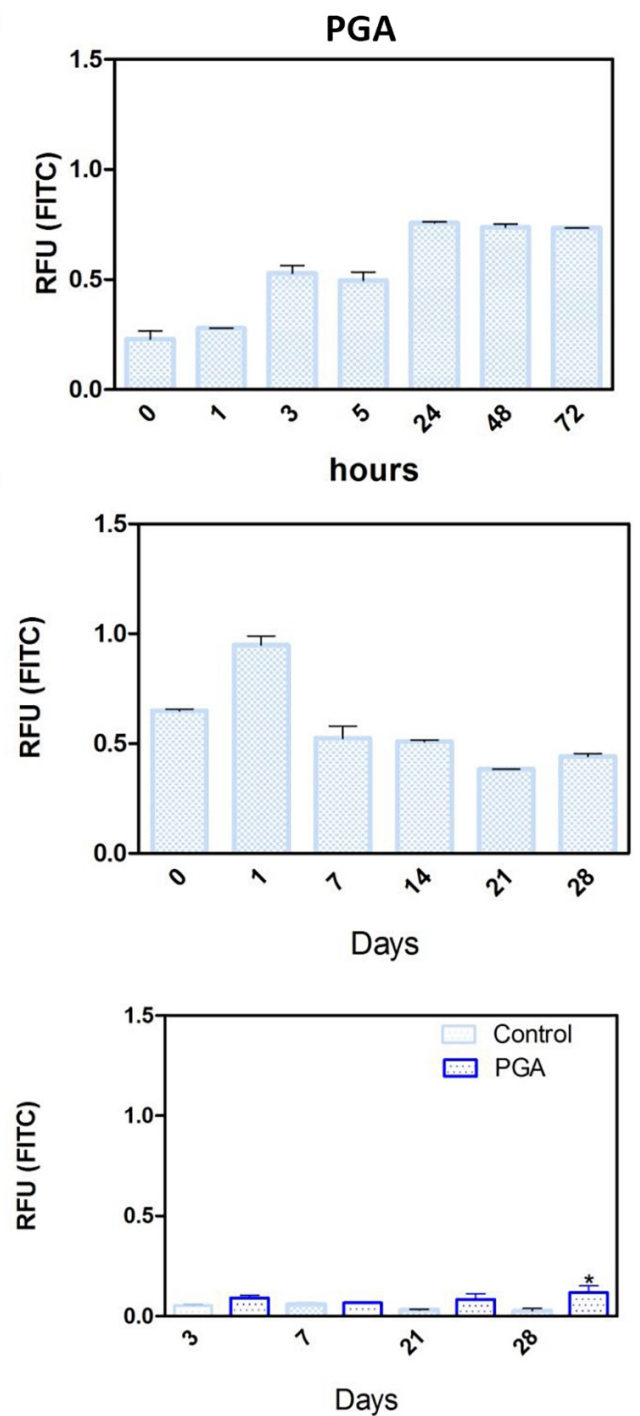

FIGURE 14 | Release of FITC from PLGA and PGA nanoparticles into a solution of $0.1 \%$ isopropanol over a short period of time (A,B), long period of time (C,D) and the release of FITC into cell culture media (E,F) from nanoparticles electrosprayed onto the basal side of PET membrane. Significant difference ${ }^{*} p<0.05$ compared to PET membrane only control, one-way ANOVA followed by Bonferroni post-test $(n=4)$. Data presented: mean $(+/-$ standard error).

FITC encapsulated. Encapsulation efficiency may explain these differences, particularly given the size difference and intervariance in size of the produced nanoparticles; however, this was beyond the scope of this study.

Degradation studies on cell cultured PET membranes decorated with FITC encapsulated nanoparticles on the basal surface, showed PLGA nanoparticles exhibited release of FITC over 28 days. The majority of the dye release was observed up to 7 days for PLGA nanoparticles with fluorescence decreasing thereafter; however, PGA nanoparticles exhibited no significant change until after 28 days, with very little detected fluorescence in comparison to PLGA (Figures 14E,F) and upon comparison to degradation in isopropanol solution (Figure 14B). This would suggest that nanoparticle degradation in cell culture media rather than in isopropanol solution offers the nanoparticles a degree of protection from degradation. The effects of the ions, proteins, lipids and other components of the culture medium may confer a degree of stability to the nanoparticles (Moore et al., 2015) and is an important factor to consider in final implant design.

\section{CONCLUSION}

In this article we have described the development of a proofof-concept composite bioactive membrane that has adequate mechanical properties, permeability and cytocompatibility. The membrane was able to maintain a monolayer of ARPE-19 cells that exhibited phenotypic microvilli structures on its apical surface while providing a sustained release of encapsulated moieties from the membrane's basal surface. 
This composite bioactive membrane exhibits the potential to act as an artificial BM and a potential treatment for atrophic AMD as a novel bioactive cell transplant substrate; to the authors' knowledge the first of its kind to be developed as a potential treatment for atrophic AMD. There are still many aspects to optimize and analyse, hence, we are now focusing on the optimization and formation of co-axially electrosprayed nanoparticles to encapsulate biologically active moieties to target drusen, and have already achieved the coaxial encapsulation of FITC with Nile red as the outer shell via electrospraying (Supplementary Figure S4). Since electrospraying involves the use of compounds dissolved in solvents, care must be taken when encapsulating biologically active moieties to ensure their activity is not compromised. We have begun screening solvents for this purpose using enzyme activity agar assays (Supplementary Figure S5). Immediate work will entail using cell systems that replicate phenotypic RPE (Pilgrim et al., 2017; Chen et al., 2020) to test this composite membrane, carrying out gene transcription and protein expression profiling on cultured primary RPE cells, as well as photoreceptor outer-segment phagocytosis assays. Further work will then move toward using moieties such as L4-F, amongst others (Vavvas et al., 2016), to target drusen.

\section{DATA AVAILABILITY STATEMENT}

The raw data supporting the conclusion of this article will be made available by the authors, without undue reservation, to any qualified researcher.

\section{REFERENCES}

Age-Related Eye Disease Study 2 Research Group (2013). Lutein + zeaxanthin and omega-3 fatty acids for age-related macular degeneration: the age-related eye disease study 2 (AREDS2) randomized clinical trial. JAMA 309, 2005-2015.

Brandl, C., Zimmermann, S. J., Milenkovic, V. M., Rosendahl, S. M. G., Grassmann, F., Milenkovic, A., et al. (2014). In-depth characterisation of retinal pigment epithelium (RPE) Cells derived from human induced pluripotent stem cells (hiPSC). Neuro Mol. Med. 16, 551-564.

Chen, L., Cheng, H.-H., Xiong, J., Zhu, Y.-T., Zhang, H.-P., Xiong, X., et al. (2018). Improved mechanical properties of Poly(butylene succinate) membrane by co-electrospinning with gelatin. Chin. J. Polymer Sci. 36, 1063-1069.

Chen, X., Singh, D., Adelman, R. A., and Rizzolo, L. J. (2020). Unstimulated, serumfree cultures of retinal pigment epithelium excrete large mounds of drusen-like deposits. Curr. Eye Res. 30, 1-5.

Curcio, C. A., and Johnson, M. (2013). "Chapter 20 - structure, function, and pathology of bruch's membrane," in Retina Anatomy and Physiology, 5th Edn, eds S. J. Ryan, S. R. Sadda, and D. R. Hinton (London: W.B. Saunders), 465-481.

da Cruz, L., Fynes, K., Georgiadis, O., Kerby, J., Luo, Y. H., Ahmado, A., et al. (2018). Phase 1 clinical study of an embryonic stem cell-derived retinal pigment epithelium patch in age-related macular degeneration. Nat. Biotechnol. 36, 328-337.

Del Priore, L. V., Tezel, T. H., and Kaplan, H. J. (2006). Maculoplasty for agerelated macular degeneration: Reengineering Bruch's membrane and the human macula. Prog. Retinal Eye Res. 25, 539-562.

Haneef, A. S., and Downes, S. (2015). Assessing the suitability of electrospun Poly(Ethylene Terephthalate) and polystyrene as cell carrier substrates for potential subsequent implantation as a synthetic Bruch's membrane. Intern. J. Polyme. Mater. Polymer. Biomater. 64, 320-332.

\section{AUTHOR CONTRIBUTIONS}

RM performed the acquisition and undertook the analyses of the data and contributed to the writing of the manuscript. IP and SK provided critical evaluation on the progress of the work and guided the work through clinical relevance. SK also provided feedback on the manuscript. AH prepared, wrote, and revised the manuscript, obtained the funding and is also leading the research.

\section{FUNDING}

This work was funded by the EPSRC, Grant reference number: $\mathrm{EP} / \mathrm{S} 001468 / 1$.

\section{ACKNOWLEDGMENTS}

The authors would like to acknowledge Alison Beckett (University of Liverpool) for her help with the SEM to image the fibrous membrane and Dr. Keith Arnold (Materials Innovations Factory, Liverpool) for his help with SEM in imaging the nanoparticles.

\section{SUPPLEMENTARY MATERIAL}

The Supplementary Material for this article can be found online at: https://www.frontiersin.org/articles/10.3389/fbioe. 2020.00456/full\#supplementary-material

Kawai, F., Kawabata, T., and Oda, M. (2019). Current knowledge on enzymatic PET degradation and its possible application to waste stream management and other fields. Appl. Microbiol. Biotechnol. 103, 4253-4268.

Kittredge, A., Ji, C., Zhang, Y., and Yang, T. (2018). Differentiation, maintenance, and analysis of human retinal pigment epithelium cells: a disease-in-a-dish model for BEST1 mutations. J. Visual. Exp. 138:57791.

Kurokawa, N., Kimura, S., and Hotta, A. (2018). Mechanical properties of poly(butylene succinate) composites with aligned cellulose-acetate nanofibers. J. Appl. Polymer Sci. 135:45429.

Liao, J.-L., Yu, J., Huang, K., Hu, J., Diemer, T., Ma, Z., et al. (2010). Molecular signature of primary retinal pigment epithelium and stem-cell-derived RPE cells. Hum. Mol. Genet. 19, 4229-4238.

Liu, Z., Yu, N., Holz, F. G., Yang, F., and Stanzel, B. V. (2014). Enhancement of retinal pigment epithelial culture characteristics and subretinal space tolerance of scaffolds with $200 \mathrm{~nm}$ fiber topography. Biomaterials 35, 2837-2850.

Lu, B., Zhu, D., Hinton, D., Humayun, M. S., and Tai, Y.-C. (2012). Meshsupported submicron parylene-C membranes for culturing retinal pigment epithelial cells. Biomed. Microdev. 14, 659-667.

Moore, T. L., Rodriguez-Lorenzo, L., Hirsch, V., Balog, S., Urban, D., Jud, C., et al. (2015). Nanoparticle colloidal stability in cell culture media and impact on cellular interactions. Chem. Soc. Rev. 44, 6287-6305.

Nowak, J. Z. (2006). Age-related macular degeneration (AMD): pathogenesis and therapy. Pharmacol. Rep. 58, 353-363.

Park, S.-Y., Kang, K.-B., Thapa, N., Kim, S.-Y., Lee, S.-J., and Kim, I.-S. (2008). Requirement of adaptor protein GULP during Stabilin-2-mediated cell corpse engulfment. J. Biol. Chem. 283, 10593-10600.

Pilgrim, M. G., Lengyel, I., Lanzirotti, A., Newville, M., Fearn, S., Emri, E., et al. (2017). Subretinal pigment epithelial deposition of drusen components including hydroxyapatite in a primary cell culture model. Invest. Ophthalmol. Vis. Sci. 58, 708-719. 
Rudolf, M., Clark, M. E., Chimento, M. F., Li, C. M., Medeiros, N. E., and Curcio, C. A. (2008). Prevalence and morphology of druse types in the macula and periphery of eyes with age-related maculopathy. Invest. Ophthalmol. Vis. Sci. 49, 1200-1209.

Rudolf, M., Curcio, C. A., Schlötzer-Schrehardt, U., Sefat, A. M. M., Tura, A., Aherrahrou, Z., et al. (2019). Apolipoprotein A-I mimetic peptide L-4F removes bruch's membrane lipids in aged nonhuman primates. Invest. Ophthalmol. Vis. Sci. 60, 461-472.

Sharma, N., Madan, P., and Lin, S. (2016). Effect of process and formulation variables on the preparation of parenteral paclitaxel-loaded biodegradable polymeric nanoparticles: a co-surfactant study. Asian J. Pharm. Sci. 11, 404-416.

Sparrow, J. R., Hicks, D., and Hamel, C. P. (2010). The retinal pigment epithelium in health and disease. Curr. Mol. Med. 10, 802-823.

Surrao, D. C., Greferath, U., Chau, Y. Q., Skabo, S. J., Huynh, M., Shelat, K. J., et al. (2017). Design, development and characterization of synthetic Bruch's membranes. Acta Biomater. 64, 357-376.

Tan, E. Y. S., Sing, S. L., and Yeong, W. Y. (2019). 60 - Scaffolds For Retinal Repairs in Handbook of Tissue Engineering Scaffolds. Sawston: Woodhead Publishing.

Thomson, H. A. J., Treharne, A. J., Walker, P., Grossel, M. C., and Lotery, A. J. (2011). Optimisation of polymer scaffolds for retinal pigment epithelium (RPE) cell transplantation. Br. J. Ophthalmol. 95:563.
Vavvas, D. G., Daniels, A. B., Kapsala, Z. G., Goldfarb, J. W., Ganotakis, E., Loewenstein, J. I., et al. (2016). Regression of some high-risk features of agerelated macular degeneration (AMD) in patients receiving intensive statin treatment. eBio Med. 5, 198-203.

White, C. E., and Olabisi, R. M. (2017). Scaffolds for retinal pigment epithelial cell transplantation in age-related macular degeneration. J. Tis. Eng. 8:2041731417720841.

Yamamoto, T., and Yamashita, H. (1989). Scanning electron microscopic observation of Bruch's membrane with the osmium tetroxide treatment. Br. J. Ophthamol. 73, 162-167.

Yeste, J., Illa, X., Alvarez, M., and Villa, R. (2018). Engineering and monitoring cellular barrier models. J. Biol. Eng. 12:18.

Conflict of Interest: The authors declare that the research was conducted in the absence of any commercial or financial relationships that could be construed as a potential conflict of interest.

Copyright (c) 2020 McCormick, Pearce, Kaye and Haneef. This is an open-access article distributed under the terms of the Creative Commons Attribution License (CC BY). The use, distribution or reproduction in other forums is permitted, provided the original author(s) and the copyright owner(s) are credited and that the original publication in this journal is cited, in accordance with accepted academic practice. No use, distribution or reproduction is permitted which does not comply with these terms. 